\title{
Feminization of Poverty in Palliative Care Giving of People Living with HIV and AIDS and Other Debilitating Diseases in Botswana. A Literature Review
}

\author{
Kang'ethe SM \\ Social Work Department, University of Fort Hare, RSA \\ Correspondence should be addressed to: Kang'ethe SM; smkangethe@yahoo.com \\ Received 22 January 2013; Accepted 13 March 2013; Published 26 April 2013 \\ Academic Editor: Felicity Z. Gumbo \\ Copyright (C 2013 Kang'ethe SM. Distributed under Creative Commons CC-BY 3.0

\begin{abstract}
Feminization of poverty in care giving of people living with HIV and AIDS and other debilitating diseases has attracted local, national and international concerns in an endeavour to surmount the challenge of poverty among women caregivers. This article highlights factors underpinning the feminization of poverty embedded in caregiving. The article has used a review of literature methodology and identifies the following as possible underpinnings of feminization of poverty: state of gender dynamics; vulnerability and poverty of women doing caregiving; inadequate support; lack of resources; and human rights violation of the caregivers. The article recommends: working to dilute cultural and patriarchal forces; training to improve the quality of service; training caregivers in tandem with the clients; awarding financial and material incentives; affording care respite to avoid fatigue and burnout; adopting poverty reduction strategies; youth participation campaigns in caring duties; donor support to sustain care programmes; and involvement of civil society to assist in care giving.
\end{abstract}

Keywords: Poverty, Palliative care giving, feminization of caregivers' poverty, HIV/AIDS.

\section{Inrtoduction}

\section{Operational Definition}

Caregivers in Botswana context usually refers to primary caregivers who are usually family members who take care of people living with HIV/AIDS and other debilitating sicknesses; or community caregivers who are community members who move from home to home to assist the primary caregivers in their care giving roles.

\section{Introduction and Background}

The magnitude of HIV/AIDS in Botswana has necessitated a multisectoral response in an endeavour to mitigate its impacts, as well as lay bare the factors that militate against a successful fight against the disease (NACA, 2009). With the $2009 \mathrm{HIV} /$ AIDS statistics showing a population based prevalence of $17.6 \%$, this calls for more efforts directed towards the fight by identifying the fuelling factors and working towards making them weaker (Central Statistics office, 2008). With care giving being one of the sector that has come out strongly to cater for the people living with HIV/AIDS especially by giving them hope and different kinds of psychosocial support that mitigates the impact and despondency associated with living with HIV/AIDS (Uys \& Cameron, 
2003; Nurses Association of Botswana, 2004; Kang'ethe, 2010), it is important to analyze the environment of care giving. This is with a goal of strengthening its operational factors so that it can contribute immensely to the course of HIV/AIDS.

With revelation that $90 \%$ of HIV/AIDS care in the globe takes place at home, the place of care giving especially at homes cannot be overemphasized (UNAIDS, 2004). Immense literature in Botswana abounds that although care giving in Botswana occupies an invaluable niche in the fight against HIV/AIDS, it suffers gross skewed gender dimension (Kang'ethe, 2011a) with women being unfairly left to handle the whole sector with only minimal assistance of men (Maundeni et. al., 2009). This has had the effect of what United Nations dubbed "feminization of poverty" (UNDP, 2008). This researcher worries that this feminization of poverty is likely to exacerbate the prevalence of HIV/AIDS as women who renders care service get weaker and ineffective to carry adequate care. And this could be true because many settings in many countries affected by HIV/AIDS indicate that more women than men are infected with the virus (UNAIDS, 2004; UNDP, 2008). With global emphasis for countries to work hard to achieve Millennium Development Goal number three that espouses gender equality and equity by the year 2015, it is important, therefore, to analyze and interrogate the environment of feminization of poverty in care giving occupation in Botswana.

\section{Article Rationale}

The article endeavours to explore possible factors responsible for "feminization of poverty" with the goal of coming with solutions or strategies to work on them.

\section{Methodology}

The article has used a literature review methodology. It has sought literature from books, journals, government publications, etc. It has also given a set of recommendations to address or mitigate feminization of poverty. While care giving in many developing countries has been relegated to women due to cultures and socializations, it has become increasingly important to indicate the danger of leaving women to solely shoulder caregiving. The literature review methodology, therefore, sheds invaluable information advocating against feminization of poverty in care giving.

\section{Factors of Feminization of Poverty in Caregiving}

\section{Gender Dynamics and Feminization of Poverty}

Across many countries, races and contexts, it is becoming clear that gender dynamics are largely responsible for the feminization of poverty on many fronts (UNDP, 2008). This necessitates gender analysis to ascertain this important assertion. According to United Nations, feminization of poverty is a structural challenge that has been caused by skewed gender power dynamics that relegate a woman to a subordinate status. In many contexts especially where traditionalism is still a great norm and thrust controlling gender dynamics, a woman is viewed as fulfilling child bearing role alongside nurturance, with other tasks taking a secondary place (Lekoko, 2009). These gender dynamics have demarcated and differentiated between the roles of men and women, with the result that women are allotted and allocated tasks that are domestic in nature that do not attract any payment, while men's occupations attract monetary rewards for most of the times (UNDP, 2008).

\section{Vulnerability of Women Caregivers}

The feminization of care giving occupation and its associated poverty has been a characteristic of most caregivers in the developing world (WHO, 2002). Cultures and socializations have denied the profession the adequate presence of men. Because men are masculine as well as better endowed with economic resources than women, they could be important human resources to offload their female counterparts in the task of care giving. Otherwise, with the current care giving in Botswana being predominantly in the hands of women, especially the relatively elderly ones, effective implementation of the care giving goals of giving those living with the 
virus a good life continue to present an arduous and uphill task for women to surmount. This has increased the environment of poverty in the care domain.

\section{Inadequate Support in Care Giving and Feminization of Poverty}

In 2001 when the current arrangements of access and dispensing avenues of ARV were not well developed in Botswana, caregivers, who were predominantly women, faced arduous tasks of providing for their clients. For people living with HIV/AIDS in the rural areas, for instance, transport to go to the ARV dispensing points such as Jwaneng or Gaborone was a challenge, alongside meeting other numerous demands of the clients (Kang'ethe, 2008). Due to the slow response and inadequacy of the social workers in assessing those living with HIV/AIDS for possible economic assistance, many deserving clients took too long to be helped while some died along the way. A few cases of some neglected clients, hungry and despondent as the caregiver went out for piece jobs have not been uncommon and have attracted documentation (Kang'ethe, 2010).

In Botswana, perhaps these are some of the conditions that made some community members develop attitudes that the community home based care programme was a dumping ground for the sick, with some pointing out that the government had passed its responsibility of care of the sick to the vulnerable caregivers, driving them to a state of poverty and vulnerability (Kelesetse, 1998). However, the dumping ground syndrome notion had been refuted by other researchers. The findings by Motana (2001) indicated that the programme was an important one and was fulfilling some of its core objectives of being vents to the congested health facilities. This researcher is of the opinion that the programme though carried by elderly women is an important one as it exploits social capital values embedded in people's culture, love, trust and the spirit of working together for a common goal (Kang'ethe \& Rakhudu, 2010).

\section{Cases of Feminization of Poverty of Caregivers}

Some studies in Botswana point to the feminization of poverty in care giving (Kang'ethe, 2006; MOH/JHPIEGO, 2009). Feminization of poverty in caregiving is evidenced when the female caregiver due to carrying out care giving tasks displays some vulnerability such as showing symptoms of poverty, either absolute or relative poverty. Absolute poverty is experienced when a caregiver lacks basic resources to maintain herself as well as facilitate care giving. This is manifested by lack of food, shelter, clothing, infrastructure such as toilets, and facilities of hygiene such as water, soap etc; while a caregiver experiences relative poverty when she finds himself/herself worse off when compared to other social environments. It is apparent that the two aspects of poverty have been experienced by the caregivers in Botswana, with no clear-cut line which one it is. In a qualitative study done at Kweneng by Mojapelo, Ditirafalo, Tau and Doehlie (2001) on care giving, $85 \%$ of the caregivers who were mainly women were not employed and often cited poverty as the main obstacle to the provision of quality care. Two of the patients lived in old derelict houses while one lived in a plastic shack, while another caregiver did not have a toilet and used her neighbour's. To corroborate and strengthen the findings of feminization of poverty in care giving, Kang'ethe's findings in Southern part of Botswana was that community home based care programmes were predominated by women, who were usually poor to adequately take care of their clients. The situation was exacerbated by inadequate support of care giving tools from the clinics (Kang'ethe, 2008). In the same vein, more evidence of feminization of poverty of the caregivers was adduced in a study conducted by the Ministry of Health in collaboration with JHPIEGO (MOH/JHPIEGO, 2009) that found that caregivers in Botswana were predominantly women who were in poverty. The concept of feminization of poverty in care giving in Botswana has therefore been a reality. 


\section{Possible Salient Factors to Address Feminization of Poverty in Caregiving}

\section{Diluting Cultural and Patriarchal Forces}

In many developing countries' contexts, role and task demarcation and differentiation have been a result and a recipe of cultural and patriarchal dynamics that have allotted the role of care giving to women and the girl children with little support from men (Lekoko, 2009). Advocacy and lobbying education should be mounted for the societies to undergo a paradigm shift in their mindset and accept to dilute cultural and patriarchal powers that have maintained the task of hospitality and care giving to be a domain of the females. The entry of men into care giving and hospitality is likely to benefit from men's masculinity strength, and importantly, their financial strength. Their leadership could also be a thrust that can turn around the care giving environment. However, this is not an easy task as these cultural and patriarchal forces have taken ages to form. They therefore require a lot of effort to de-culturalize or reduce the effects of the patriarchal mindset deeply rooted in most of the societies especially of the developing world.

\section{Training to Improve the Quality of Service}

Training is the mainspring of knowledge. It gives one confidence, control and an opportunity to make informed decisions. Training would have a positive impact in planning, decision making, managing stress and burnout among the caregivers. Training among the caregivers encourages selfreflection, self-knowledge, self-actualization and strengthens the caregivers' coping mechanisms. If full training may not be tenable due to financial constraints and the fact that caregivers lack time, refresher and on-going training courses, regular stress management sessions, development seminars, need to be provided by care programmes to upgrade caregivers' skills and knowledge (Uys \& Cameron, 2003). This is likely to strengthen them to face the challenges of disease dynamics. Training should be geared to fill skills and knowledge gaps in care giving that are observable by the care programme or other stakeholders; or which caregivers themselves identify to be hindering the care process. It is recommendable that both theoretical and hands-on training on home and communitybased care be prioritized not only to the caregivers but to the family members as well. The family members need to be able to assess the disease progression of the client (Uys \& Cameron, 2003).

\section{Training Caregivers in Tandem with the Clients}

While offering education and information to the caregivers, it is necessary that clients be included so that both can be equipped to manage the challenges of the disease progression and sometimes disability. This will facilitate information sharing between the client and the caregiver and can ease the burden of care on the caregiver. It will also help facilitate a smooth relation between the client and the caregiver, and the client's decision-making capacity over his/her care, is likely to go up. This is important because conflicts between the caregiver and the client usually emanates more often from the clients' poor understanding of the conditions of care giving (Uys \& Cameron, 2003).

\section{Awarding Financial and Material Incentives to Caregivers}

Feminization of poverty in caregiving can be mitigated or reduced by incentivizing caregivers either with money or food items in order to raise their working morale; or remove stress and distress from lack of food to the caregiver. Money to settle challenges such as transport is critical (UNAIDS, 2000). Programmes and plans must be put in place to streamline different forms of incentives. The Government, complemented by civil society bodies and donors should take the challenge of initiating financial and material incentives to the caregivers (Kang'ethe, 2011b). This researcher would recommend that the government of Botswana borrows a leaf from the Mozambique government which has a policy to give its caregiver volunteers $60 \%$ of the minimum wage rate in the country. This would to some extent cushions the poverty and reduces feminization of the caregivers (http//www.irinews.org./AIDsreport, 2005). Although Botswana government has a policy to offer food to its people living with HIV/AIDS, there is none for the 
caregivers. The food basket issue also presents a challenge to the caregivers in that it is usually standardized for ease of management and administration. It is fair that each client should be individualized and a basket befitting his/her nutritional needs be given depending on his/her ailment. Since clients have different nutritional needs and requirements, it is recommended that the food basket not be standardized. Timely and regular provision is also critical.

\section{Care Respite to Avoid Fatigue and Burnout of Caregivers}

Care giving in Botswana has been found to be burdensome and a bottleneck to quality care. Many caregivers find themselves grappling with problems beyond their capacity in terms of burden and knowledge. Perhaps its time that care giving is boosted by putting in place day care centres to afford the caregivers an opportunity to get care respite (Daily News, 2002). Unfortunately that has not happened. However, it would also be vital for caregivers not to exceed their capacity to avoid stress and burnout. This is to sustain their health and well-being. It is necessary that the programme under which a caregiver is working helps to assess his/her capacity professionally. This is because many caregivers may not be in a position to assess their breaking point, especially due to emotional attachment and love they may have for their clients (John Bowlby (1997) quoted by Kang'ethe, 2006). Caregivers need to accept and learn to let others help and feel no guilt in failing to do everything, earning a little time for respite so that they can replenish their working energies or have their working batteries recharged (Lifeline Health Care Magazine, 2005). Otherwise, it would be advisable, therefore, that most of the care giving done by the caregivers be appropriately carried out in a caring institution or a hospice.

\section{Adopt Poverty Reduction Strategies}

The poverty of caregivers as exemplified in some care programmes in Botswana and in other many resource-strapped countries need to be addressed if care of people living with HIV/AIDS at homes is to be done effectively. This is worrying in that literature abounds that $90 \%$ of care of PLWHA takes place at home (UNAIDS, 2004; WHO, 2002). This is because AIDS is a poverty friendly disease and thrives well in a poverty stricken environment (Kang'ethe, 2010). Assistance to caregivers by Government, civil society bodies and private sector to start income generating projects such as pig keeping, poultry farming, bee farming, brick making, candle making etc should be encouraged. The Government of Botswana needs to come up with a strategy to rescue the caregivers out of poverty. Although the care of the carers' policy has been theoretically been adopted, but it has not been operationalized (MOH/JHPIEGO, 2009). Advancing the caregivers' stipends on either weekly, monthly or a food basket (caregiver food basket) would be a welcome gesture. Giving soft loans for the caregivers to start simple but productive income generating projects would augur well for them. Involvement of men in the care domain is also welcome

\section{Youth Participation Campaign in Caring Duties}

All public fora such as churches, "kgotla"(chief's) meetings, women group meetings, youth group meetings, HIV/AIDS campaigns and learning institutions need to advocate and address the need for the youth to help in care giving. This is because empirical findings in many caring programmes in Botswana and elsewhere have found that the role of care giving has principally been left to the elderly, especially women. The youth besides being physically fit could be more knowledgeable in some aspects of care than the elderly. The youth could also be an outlet for the elderly to get some respite. Schools could be good advocacy fronts to challenge children's and youth's minds to effect paradigm shift of the cultural stereotypes that dictate that care giving is a preoccupation of women, especially the elderly.

\section{Need for Donor Support to Sustain Care Programmes}

Most care programmes, especially in the developing world suffer socio-economic blows due to inadequate or lack of Government or donor support. Withdrawal of donors from Botswana after it was 
upgraded to an upper middle income class made most NGOs and CBOs that used to get funding from such donors be disadvantaged. Care giving was not spared either by the detrimental effect (The Beat, 2000). However, many care programmes the world over owe their success and sustainability to donor funding. The Ikahlas Community Care Centre for the Intravenous Drug Users (IDUS) in Malaysia, for example, has benefited from European Commission, Dutch Agency and Malaysian AIDS Council (UNAIDS, June, 1999). The assistance that Mellinda Gates \& Merck and Company is giving to Botswana to fight HIV/AIDS through ACHAP (African comprehensive HIV/AIDS Partnership), an NGO, is highly welcome and other donors should be encouraged (ACHAP Update, 2005). The call for donor assistance and mobilization for sustainability of programmes need to strengthened by Government, civil society bodies, private sector and private individuals. Community acceptance and mobilization of community leaders to support CHBC programmes would be a move in the right direction. Community ownership of the programmes and involvement of men could probably shape sustainability of the programmes.

\section{Need for Civil Society to Assist in Care Giving}

Assistance to caregivers from civil society stakeholders is critical. The involvement of men is critical and desirable. The call is in line with the 1995 AIDS Day theme of "shared rights, shared responsibilities" (Kang'ethe, 2006). Kofi Annan, the immediate past UN Secretary General (1997-2006) emphasized the need to involve everybody in the job of fighting HIV/AIDS at the UN General Assembly Special Session on HIV/AIDs (UNGASS) in June 2001 by challenging all to recognize and prioritize AIDS as a problem for all (UNAIDS, 2001). Pivotally, NGOs and CBOs are good community mobilization vehicles to advocate for care process in the community. NGOs especially are known for advocacy for attitudinal change among the people. They can assist the communities through community mobilization and advocacy to understand the need for men and youth to assist female caregivers in their tasks so that they may not get overwhelmed or suffer burnout.

\section{Conclusion}

Care giving is an important and invaluable occupation that has served a very important niche in the hospitability services in many countries of the developing world. However, it has been associated with women whose poverty situation has exacerbated their capacities to cope. This poverty has painted a gloomy picture as far as the quality of care giving is concerned. Measures and strategies to dilute cultural and patriarchal forces that have demarcated and allotted the hospitality services need to be mooted urgently. This is to usher in the male factor into the occupation with the hope of improving its leadership and inject financial power into the occupation. Care giving needs a paradigm shift through civil society putting a strong foot to assist care giving; putting in place incentives, stipends and allowances to make it motivational. Feminization of poverty has to be addressed if care of people living with HIV/AIDS at homes is to realize adequate dividends.

\section{References}

ACHAP (2005). 'ACHAP Update,' December; 2005.

Botswana Daily News. 'Day Care Centres to Complement CHBC Programme,"15th August 2002.

Central Statistics Office (2008). 'Preliminary Botswana HIV/AIDS Impact Survey III (BAIS III).Gaborone: Government Printer,' http//www.irinews.org./aidsreport.asp? (2005). Mozambique. Financial Incentive to Attract Home Based HIV/AIDS Caregivers. Retrieved on 10/1/2005.

Kang'ethe, S. M. (2006). 'Contribution of Caregivers in Community Home Based Care Programmes. The Case of Kanye, Botswana,' Unpublished PhD Dissertation in Social Work, Department of Social Work, Faculty of Social Sciences, University of North West.

Kang'ethe, S. M. (2008b). "Challenges that the Referral System Poses to Care Giving as Exemplified by Thinking the Kanye Community Home Based Care (CHBC) 
Programme in Botswana," Maatskaplike Werk, 44 (4), Pp 355-368.

Kang'ethe, S. M. (2010). "Exploring the Psychosocial Palliative Care Giving Position Associated with Kanye Home Based Care Programme," Botswana Notes \& Record Journal. Vol 42: Pp 112-153.

Kang'ethe, S. M. (2011a). 'Gender Discrepancies Abound in Community Home Based Care Programme (CHBC) in Botswana,' S. Afr. Fam. Pract. 2011.7. Vol 53. No 5. Pg. 467-473.

Kang'ethe, S. M. (2011b). "Exploring the Awarding of Incentives to Raise Care-Giving Productivity in Botswana Care Programmes as Exemplified by the Kanye Care Programme," Maatskaplike Werk 2011: 47(1) P/1-14.

Kang'ethe, S. M. \& Rhakudu, M. (2010). "Religious Education book for form 2," Heinemann Publishers, Gaborone.

Kelesetse, N. M. AIDS (1998). 'Home Based Care and the Status of Women in Botswana: A Case Study of Mogoditshane,' Gaborone: BA Thesis, University of Botswana, Faculty of Sociology.

Lekoko, R. N. (2009). 'A Generation in Jeopardy. Sexually Active Women in Partriarchal Settings and HIV and AIDS,' In: Maundeni T, Osei-HwedieBZ, Mukaamambo E, Ntseane PG, editors. Male Involvement in Sexual and Reproductive Health. Prevention of Violence and HIV/AIDS in Botswana. Cape Town: Made Plain Communications. p. 91104.

Lifeline Health Care Magazine (2005). 'Caring for the Caregiver,' Heart Foundations, South Africa.

Maundeni, T., Osei-Hwedie, B. Z., Mukaamambo, E. \& Ntseane, P. G. (eds) (2009). 'Male Involvement in Sexual and Reproductive Health,' Prevention of Violence and HIV/AIDS in Botswana. Made Plain Communications, Cape Town.

Ministry of Health/JHPIEGO (2009). 'Situational Analysis of the Care and Treatment of PLWHA in Botswana,' Draft Report.
Mojapelo, D., Ditirafalo, T., Tau, M. \& Doehlie, E. (2001). 'Client Satisfaction and Providers' Perspectives of Home-Based Care in Kweneng District, Botswana,' Unpublished Report. Gaborone.

Motana, M. P. (2001). 'Assessment of CHBC from a Nurses's Perspective,' Published Absreact No 70 on Ist. Regional CHBC Conference. March 2001. Boipuso Hall, Gaborone.

National AIDS Coordinating Agency (2009). 'Ministry of State President, Government of Botswana,' The Second National Strategic Framework for HIV and AIDS: 2010-2016.

Nurses Association of Botswana (2004). 'Caring for the Care Givers,' Gaborone: Kgotla Designs.

The Beat (2000). Botswana Network of AIDS Service Organizations. September issue; 2000.

UNAIDS (1999). Comfort and Hope. Six Case Studies on Mobilizing Family and Community Care for and by People Living with HIV/AIDS. Geneva, Switzerland.

UNAIDS (2000). 'Caring for Carers. Managing Stress in those who Care for People with HIV and AIDS,' UNAIDS Case Study, Geneva, Switzerland.

UNAIDS (2001). Keeping the Promise. Summary of the Declarations of Commitment on HIV/AIDS. United Nations General Assembly Special Session (UNGASS), June. New York.

UNAIDS (2004). Women and AIDS. An Extract from the AIDS Epidemic Update. December, Geneva, Switzerland.

UNDP (2008). 'Situation Analysis on Gender Based Violence in Botswana,' Draft Report. Participatory Education, Evaluation and Research.

Uys, L. \& Cameron, S. (2003). 'Home Based HIV/AIDS Care,' Cape Town: Oxford University Press.

WHO (2002). 'Community Home-Based Care in Resource - Limited Settings: A Framework for Action,' 20 Avenue Appia, 1221 Geneva 27, Switzerland. 